\title{
Children's voices in system reform: A case study on children and young people's participation within the modernisation of Child, Youth and Family
}

\author{
Luke Fitzmaurice Otago University; Oranga Tamariki, Aotearoa New Zealand
}

\begin{abstract}
INTRODUCTION: In 2015, an independent panel was appointed to overhaul Aotearoa New Zealand's care, protection and youth justice systems. This article discusses the mechanisms used to involve children and young people in that review and evaluates the extent to which these mechanisms lived up to best practice.

METHODS: The article takes a case study approach: exploring the ways in which the Expert Panel enabled children and young people to have a meaningful role in the process. The author was a member of the Expert Panel Secretariat, which supported the Panel during the review. The impact that young people's voices had on the process motivated this research in order to explore what made their input effective, and what could have been improved.
\end{abstract}

FINDINGS: The Expert Panel made young people's participation in the review meaningful by valuing their lived experience and providing the necessary support to enable them to have their voices heard. Although more could have been done to reduce the risk of filtering and assumed representation, the Panel's approach to involving children and young people in the design process was strongly in line with a childhood studies approach to children and young people's participation.

CONCLUSIONS: The outcomes of this process challenge the assumption that giving young people decision-making power is what makes this type of process effective. It may be that decision-making influence, not decision-making power, is what makes young people's participation meaningful. The lessons learned from this process should guide the next phase of system reform.

KEYWORDS: participation, children's participation, youth participation, children's rights, state care

In April 2015, the Minister of Social

Development announced an overhaul of

Aotearoa New Zealand's care, protection and youth justice systems to be led by an independent panel. The Expert Panel's terms of reference required them to consider "the extent to which Child, Youth and Family's current operating model is child-centric and focused on improving results for children and young people" (Ministry of Social Development, 2015, p. 2). The terms of reference were broad, with the Panel being given the mandate to recommend fundamental, system-level changes. In order to do this, the Expert Panel sought input from a range of stakeholders, the most important of which were children and young people themselves.

This case study examines children and young people's participation in the review of Child, Youth and Family. It evaluates
AOTEAROA

NEW ZEALAND SOCIAL WORK 29(1), 41-52.

CORRESPONDENCE TO: Luke Fitzmaurice lukefitzmaurice@gmail.com 
the three mechanisms used by the Panel to engage with children and young people: a series of one-on-one interviews; a number of co-design workshops; and a Youth Advisory Panel. It summarises the literature on children and young people's participation in decision-making and examines the extent to which the processes used to engage children and young people lived up to best practice.

A full overhaul of Child, Youth and Family is now under way, with a replacement service (the Ministry for Vulnerable Children, Oranga Tamariki) due to begin operating on 1 April, 2017. The reforms are far-reaching, with a four-year programme of work now in progress to design and implement the new services. This article concludes with recommendations for how the voices of children and young people might guide that process, just as they guided the review, so that the future care and protection system may be truly child-centred.

\section{Barriers and enablers to children and young people's participation}

Before discussing children and young people's participation in the review, it is useful to summarise the literature on participation in decision-making for children in care.

Article 12 of the UN Convention on the Rights of the Child gives children the right to participate in decisions about their lives, but exactly how that participation should happen remains the subject of discussion. The emergence of children's participation frameworks from the 1990s onwards was designed to address this issue. The work of Roger Hart (1992) was one of the first models to categorise different types of children's participation. Hart's Ladder of Participation describes eight levels of participation, from manipulation, decoration and tokenism at the bottom of the Ladder to child-initiated, shared decisions with adults at the top. Hart's Ladder has since been developed further by others. Treseder's (1997) Degrees of Involvement is one alternative, developed in response to the criticism that the Ladder model is too linear and overly simplistic. The "Pathways to Participation" framework (Shier, 2001) is perhaps the best known adaptation of the Ladder approach, building on Hart's work by describing the steps needed to embed each level of participation in practice.

More recently, there has been a shift away from the frameworks approach towards more nuanced ways of enabling children and young people's participation (Malone \& Hartung, 2010). The models developed by Hart and Shier have been criticised for remaining rooted in adult-centric processes (Thomas \& Percy-Smith, 2012), or for perpetuating the dominant sociocultural image of children rather than treating them as social actors (Mason \& Hood, 2011). It is now recognised that meaningful engagement with children and young people is a fluid process with a range of factors influencing the appropriate form of participation (Horwath, Kalyva, \& Spyru, 2012).

\section{Factors affecting participation for children and young people in care}

There are a number of barriers affecting participation for children and young people in care. Firstly, they are often prevented from meaningfully participation in decisions due to their perceived vulnerability (Powell \& Smith, 2009). This can be a valid concern, but the tension between the need for protection and the right to participate is often a false dichotomy (Atwool, 2006) and the responsibility to protect children and young people can develop into overprotection (Powell \& Smith, 2009). Secondly, decisions relating to children and young people in care often involve highly charged interactions between adults, which can diminish a child or young person's opportunity to have their voice heard (Atwool, 2006). Social workers are often tasked with determining what is in the child or young person's best interests, and as the best interests test is discretionary, this can lead to adults silencing or sidelining children's and young people's views (Tisdall, 2015a). Thirdly, the care system 
itself can also be a barrier to participation. Organisational systems and structures do not always prioritise listening to children's and young people's views (Bessell, 2011) and opportunities to participate may be further limited by risk-averse social work agencies (van Bijleveld, Dedding, \& Bunders-Aelen, 2015).

\section{Factors affecting participation generally}

Participation in decision-making requires adults to view children and young people as social actors with the capacity to meaningfully contribute. Smith (2002) notes that "age and stage"-based views on the capacities of children have been largely discredited, but persist in practice. Meaningful participation also requires viewing children and young people as unique individuals, because the experiences of one child or young person cannot be assumed to be representative of all children and young people (James, 2004). There is a risk of assumed representation whereby, once a children's participation structure is set up, those participants become the voice of children (Thomas \& Percy-Smith, 2012). Secondly, meaningful participation can depend on the extent to which adult intermediaries filter, interpret or translate children's and young people's views (James, 2007). Adults can filter a child's or young person's opinions without intending to, and in some contexts children's voices may be supplemented by those of professionals, which can determine how much weight the child's or young person's view should be given (Tisdall, 2015a). There may also be a selection bias whereby only those children and young people considered mature or articulate enough are invited to participate in decision-making, further marginalising disadvantaged groups (Horwath et al., 2012). There is a risk that children's and young people's views can be excluded when they do not follow the rules of certain spaces, such as government policy-making (Tisdall \& Davis, 2004). Children's and young people's views may not sit neatly with adult agendas.

\section{Factors exacerbated by being in care}

Trusting relationships are crucial to enabling children and young people to have a voice in decision-making (Cossar, Brandon, \& Jordan, 2014) but, for children in care, those relationships may not exist, severely limiting the opportunities to have their voice heard (Ashton, 2014). Complaints mechanisms are often ineffective without having a trusted adult advocate, even when those mechanisms are well known (Cashmore, 2002). Independent facilitators can be crucial in this respect, and youthled independent advocacy organisations can make a significant difference (Bessell, 2011). Professional facilitators can also help adult decision makers who want to enable children and young people to have input into decisions, but may not know how to do this effectively (Thomas \& Percy-Smith, 2012). The marginalised position of children and young people in society also means they are dependent on adults to facilitate participation (Lansdown, 2010). This can become an issue in research with children and young people, where the need for informed consent can lead to increased gatekeeping by parents and other adults (Powell \& Smith, 2009).

\section{The need for a participation ecosystem}

There are several, broader barriers preventing meaningful engagement with children and young people. These include the lack of a participation culture (Thomas \& Percy-Smith, 2012), a lack of participation infrastructure (Lansdown, 2010), a lack of understanding of what meaningful participation entails (Tisdall, 2015a), and a lack of research on the impacts that participation can achieve (Crowley, 2015). Together these could be labelled a participation ecosystem.

A culture of participation requires all professionals to adopt participatory practices rather than leaving this up to specific individuals (Thomas \& Percy-Smith, 2012).

Legislation enabling children and young 
people to participate does not guarantee that participation will occur (Atwool, 2006), and a change in practice requires a change in attitudes, along with the development of the necessary skills (Cashmore, 2002). This includes cultural competency, as what constitutes effective participation may differ across different cultures (Shier, 2010).

This latter point is crucial in Aotearoa New Zealand. For Māori, involvement in decision-making has significance as an expression of partnership, protection and participation in terms of Te Tiriti o Waitangi (Gray, 2002). Te Ao Māori principles may have particular importance in this context. For example, the principle of whakamanawa refers to creating a space in which Māori are empowered and supported to participate, and the principle of rangatiratanga focuses on self-determination and the rights of Māori to be involved in decisions which affect them (Child, Youth and Family, 2016). Such principles have unique implications in this context, where supporting children and young people to be heard and valuing their contributions are important elements of making participation meaningful (James, 2007). For Pasifika children and young people, individualised conceptualisations of participation may be culturally inappropriate (Suaalii \& Mavoa, 2001). Vaioleti's (2006) Talanoa framework was developed as a culturally appropriate methodology for research with Pasifika people, and there have been a number of resources developed for the purpose of engaging with young people in a culturally appropriate way (see, for example: The Werry Centre, 2009; Le Va, 2016). While a full discussion of culturally appropriate participation methods is beyond the scope of this paper, it is crucial that efforts to develop a participation culture take this into account.

Participation infrastructure involves elements of time, space and approach. Children and young people's participation often occurs as a one-off process rather than a thorough, on-going engagement
(Lansdown, 2010; Marchant \& Kirby, 2004; Sinclair, 2004). Children need to be able to have on-going input, rather than being only asked to contribute their views at one particular time (Vis \& Thomas, 2009). Participation is most effective when children's inclusion in decision-making is an on-going and integral part of their lives (Smith, 2011), and there is a need to recognise children's participation in their everyday spaces (Percy-Smith, 2010). While the use of safe spaces can be helpful, this can also isolate children and young people from decisions instead of making them more involved (Tisdall, 2015b).

Often there is a lack of shared understanding about the purpose of participation, with children and young people believing they are there to influence decisions and adults viewing participation as more of a learning exercise (Tisdall, 2015a). Even when children and young people are asked for their views, decision-makers may not expect those views to actually influence decisions (Crowley, 2015). Children and young people may also have differing views from adults on when their participation in decision-making is appropriate (van Bijleveld et al., 2015). This may be, in part, due to a lack of research on the impacts of participation. While there is a wealth of literature on how and why to involve children and young people in decision-making, there is less research about what policy impacts can be achieved (Crowley, 2015). Others have cited a lack of impact measurement as one of the barriers to a more comprehensive approach to participation (Lansdown, 2010; Sinclair, 2004).

A theme throughout the literature is that enabling children and young people to have a meaningful role in decision-making requires taking a broad approach to participation, where adults value the unique contributions that children and young people can make. The following sections examine the extent to which this happened during the Expert Panel's review. 


\section{Background and approach of the Expert Panel}

The appointment of the Expert Panel followed a number of similar reviews in the preceding years, each of which found that the care and protection system was not sufficiently child-centred. These included a ministerial inquiry on the welfare, safety and protection of children in Aotearoa New Zealand (Smith, 2011), a review of the Child, Youth and Family complaints system (Broad, 2013) and a comprehensive review of the workload and caseload of social workers (Office of the Chief Social Worker, 2014). In addition, the White Paper for Vulnerable Children had introduced a series of government-wide changes aimed at better protecting vulnerable children and preventing harm, abuse and neglect (Ministry of Social Development, 2012). Multiple reviews had failed to reverse an increase in findings of abuse and neglect.

The Expert Panel adopted a number of design principles to guide their work, the first of which was "placing the child at the centre of the design." The Expert Panel's interim report described this as "the anchor" of their work (Expert Panel, 2015a, p. 117). This approach prioritised understanding children and their context (see Figure 1).

This was expanded on in the Expert Panel's final report, which described "a collaborative approach which places children and young people at the centre of the operating model design" (Expert Panel, 2015b, p. 35). The "voice of experience" was one of three key drivers of the Expert Panel's design work (see Figure 2).

\section{Involving children and young people in the design}

In total, 78 children and young people participated in the review through three engagement mechanisms. The first was a series of one-on-one interviews with children and young people who had experienced the care system. The interviews were conducted in partnership with a human-centred design

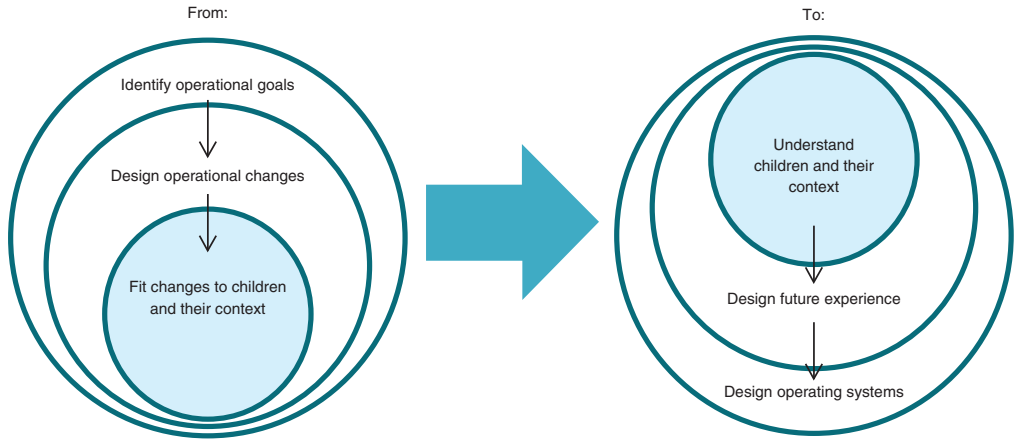

Figure 1: Expert Panel's Design Approach (Expert Panel, 2015b, p. 36)

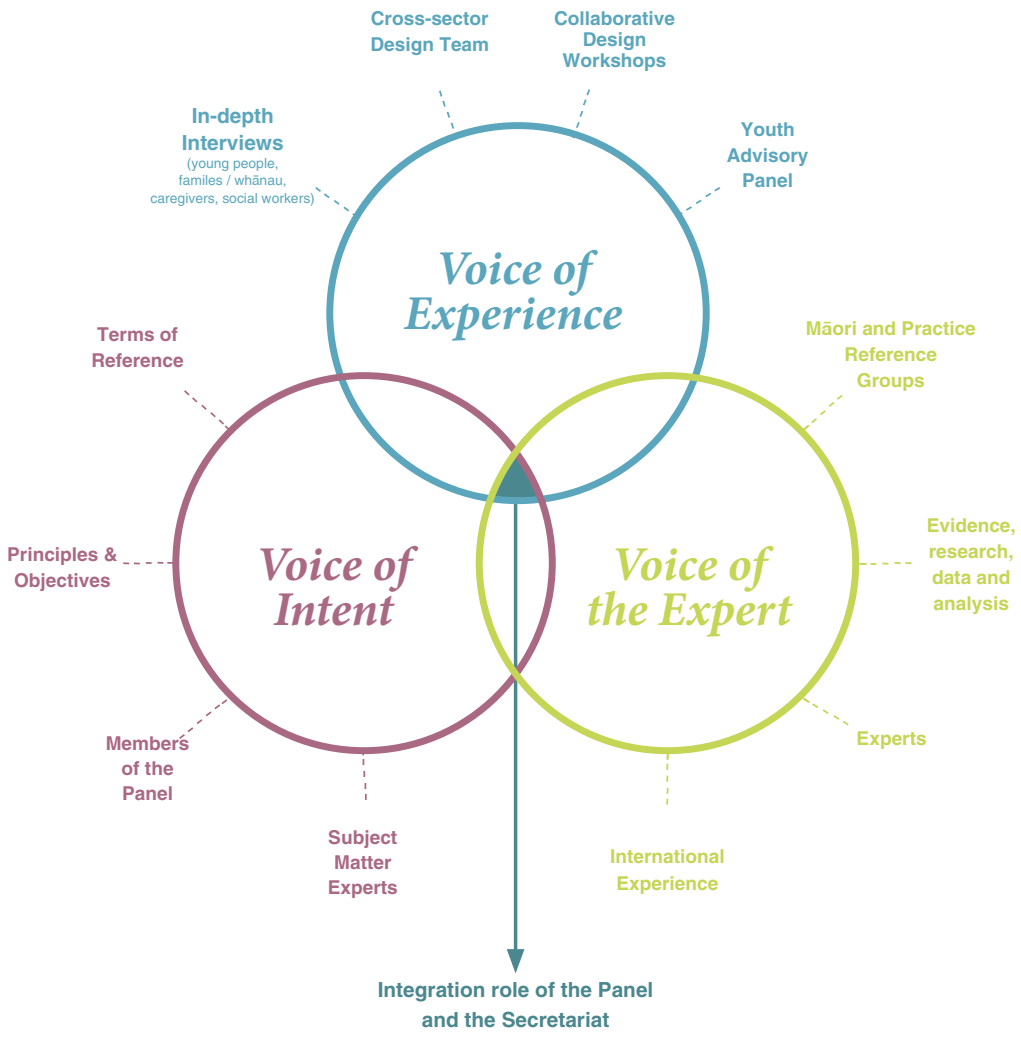

Figure 2: Design Shifts for a Child-centred System (Expert Panel, 2015b, p. 36)

agency based in Wellington. Interviewees were nominated by non-government organisations (NGOs), the Office of the Children's Commissioner and Child, Youth and Family (Expert Panel, 2015a, p. 40).

Twenty-five children and young people were interviewed, with an attempt made to have a broad demographic profile, including a mix of Māori and non-Māori, male and female, 
and geographical representation from across Aotearoa New Zealand (Expert Panel, 2015b, p. 255).

The interviews focused on children and young people's experience in the system, with an emphasis on what worked, what did not work, and what they would like to be different for children and young people in the future. The interviews were designed to be in-depth, with some lasting several hours. Before the interview, participants were given a camera to record things which made them either happy or sad, and these photos formed the basis of the initial interview questions (Expert Panel, 2015a, p. 40).

This method was also used for interviews with whānau, caregivers and social workers, but there was a specific protocol in place for the interviews with children and young people. The protocol included a requirement that interviews be conducted in pairs, with one specialist in human-centred design and another in working with vulnerable children and young people (Expert Panel, 2015b, p. 253).

There were also a number of co-design workshops held with children and young people, run in partnership with Youthline, a youth development NGO. As with the one-one-one interviews, this method was also used with whānau, caregivers and social workers, but there was a specific protocol in place when children and young people were involved (Expert Panel, 2015b, p. 257). The aim of the workshops was to develop ideas for the future operating model. Participants were nominated by Youthline, the Office of the Children's Commissioner and Child, Youth and Family, with Youthline having a central role, both in facilitating the workshops and in providing participants with pastoral support before and afterwards (Expert Panel, 2015b, p. 257). In total, 47 children and young people participated in the workshops (Expert Panel, 2015b, p. 256).

A Youth Advisory Panel was also set up to provide advice on a number of aspects of the review. The Youth Advisory Panel comprised care-experienced young people and was one of three reference groups established to support the Expert Panel (Expert Panel, 2015a, p. 18). However, unlike the other reference groups, the Youth Advisory Panel provided advice directly to the Minister of Social Development as well as providing advice to the Expert Panel (Expert Panel, 2015b, p. 249).

The Youth Advisory Panel was established by the Office of the Children's Commissioner, following a request from the Minister of Social Development. Awhina Buchanan was the representative from the Office of the Children's Commissioner who facilitated the Youth Advisory Panel process. Buchanan cited the timeframes for the review process, the degree of pastoral support required for the young people involved and the financial cost as some of the main factors which influenced the form of the Youth Advisory Panel (personal communication, May 20, 2016). Eight young people between the age of 15 and 23 were chosen, all of whom were currently, or had previously been, in care. The Youth Advisory Panel convened multiple times throughout the review process, with the same young people involved each time to ensure that an appropriate level of support could be provided (A. Buchanan, personal communication, May 20, 2016). They were recruited through nominations from the Office of the Children's Commissioner, the Expert Panel Secretariat or Child, Youth and Family social workers. Most members of the Youth Advisory Panel had previously been involved in at least one youth participation process through the Office of the Children's Commissioner or Child, Youth and Family.

\section{Outputs from the interviews, workshops and Youth Advisory Panel process}

The outputs from these processes were visible throughout the Expert Panel's interim and final reports. The interviews with children and young people were collated and summarised into a series of "insights". Eight 
insights from the interviews were presented in the interim report (Expert Panel, 2015a, pp. 40-45). Some of the children and young people's comments were included directly in the report, as were some of the photos they took prior to the interviews. Insights on specific topics were also shared with the Expert Panel and the Expert Panel Secretariat (which supported the Panel's work within the review) throughout the design process (Expert Panel, 2015b, p. 254).

The outputs from the workshops were not directly visible, as they were intended to inform the Expert Panel's wider design process rather than sit as stand-alone outcomes. Referring to the workshops in general (not just the six which involved children and young people), the Expert Panel's final report states the workshops were used to come up with unconstrained "what if" ideas, and that workshop participants were chosen who could contribute to and support "outside the square" thinking (Expert Panel, 2015b, p. 256). Those ideas were then further developed, tested and refined by the Expert Panel and the Expert Panel Secretariat.

The Youth Advisory Panel developed a set of success factors that they used to test some of the concepts developed by the Expert Panel and the Expert Panel Secretariat throughout the design process. The success factors were descriptions of what a child or young person would experience in an improved care and protection system, from that child or young person's individual perspective (A. Buchanan, personal communication, May 20, 2016). Although they were not included in the final report, the success factors were designed to hold adult decisionmakers accountable and ground their work in the voices of young people. The Youth Advisory Panel developed their success factors independently and used them as a checklist when adults were presenting ideas for the future operating model (A. Buchanan, personal communication, May 20, 2016). Each Youth Advisory Panel member also wrote a postcard addressed directly to the
Minister of Social Development, stating one thing which that young person would like the Minister to consider while reading the final report. Many of the postcards were also included in the report itself.

\section{Quantifying the impact of participation}

A full examination of the impact that children and young people's participation had on the review is beyond the scope of this case study, but it is useful to briefly touch on the impact of the Youth Advisory Panel in particular.

When the Minister of Social Development released the Expert Panel's report, she was particularly thankful to the Youth Advisory Panel for their role in the process. Describing the Youth Advisory Panel as "brave, intelligent and inspiring," she spoke about them bringing her to tears on several occasions. "This is happening to us," she recalled them saying, "but no one ever asks us what we want" (Tolley, 2016, para. 9). Expert Panel member Duncan Dunlop stated that this was more than just rhetoric; the Youth Advisory Panel had a significant impact on key decision makers, including the Minister. In his words, the direct involvement of young people at such a high level "gave integrity to the Expert Panel's work" (personal communication, June 3, 2016). Awhina Buchanan described the Youth Advisory Panel's ability to speak with the Minister directly as a unique and defining feature of the process (personal communication, May 20, 2016).

Based on these comments, it would appear that the Youth Advisory Panel had a significant effect on some of the decisions that were made. Quantifying the impact of the Youth Advisory Panel's work would be a valuable area for further research because, if this impact could be proven, it would be an example of how the quality of children and young people's participation does not necessarily depend on the degree of decision-making power they are given. Close 
proximity to a powerful decision-maker with a broad mandate was what made the Youth Advisory Panel process meaningful, not the degree of autonomy they were given to make decisions themselves. It could be that decision-making influence, rather than decision-making power, is what makes children and young people's participation more meaningful.

This would be a hypothesis worth testing. As already noted, there is a lack of research on the policy impacts that can be achieved by involving children in decision-making. A more thorough examination of the impact that the Youth Advisory Panel had would therefore be valuable.

\section{Evaluating the three participation mechanisms}

The following section discusses selected themes from the literature on children's participation, examining the extent to which the methods used by the Expert Panel reflected best practice.

\section{Viewing children and young people as social actors}

In any participation process, it is essential that children and young people are viewed as social actors, which is not only about letting them speak, but also about exploring the unique contribution that their perspectives can provide (James, 2007). One barrier to participation is that decisionmakers do not always expect children and young people to influence decisions, even when they are given an opportunity to speak (Crowley, 2015).

The Expert Panel's design approach helped address this by placing significant emphasis on children and young people's personal stories. Children and young people's participation was grounded in their own personal experience; they were supported to speak as "experts in their own lives" (D. Dunlop, personal communication, June 3, 2016). Decisions were then made based on those personal stories. By emphasising the importance of understanding children and their context (see Figure 1), the Expert Panel adopted a process that was strongly in line with a childhood studies approach to children's participation.

\section{Recognising children and young people's vulnerability}

Balanced against the need to recognise children and young people as social actors is the importance of recognising their potential vulnerability. There is a risk that children and young people who have experienced trauma may be further harmed if participation does not occur in an ethical way (Cater \& Overlien, 2014; Lansdown, 2010). Although this risk can be overstated, researchers have a responsibility to ensure that children and young people who participate in decision-making have their vulnerability taken into account.

The support provided to the children and young people who participated in the interviews, workshops and Youth Advisory Panel addressed this risk. There were comprehensive protocols in place for each process, which included cultural considerations (Expert Panel, 2015b, p. 253). Facilitators ensured that pastoral support remained available long after the children and young people's involvement in the review had concluded (A. Buchanan, personal communication, May 20, 2016). The one-onone interviews were conducted in a place where the interviewees felt comfortable (Expert Panel, 2015b, p. 253).

\section{Accountability, independence and the need to avoid filtering}

The risk of children and young people's voices being filtered by adult opinions was addressed, but not entirely mitigated. The success factors that the Youth Advisory Panel developed helped address filtering issues, as they could be used to hold decision-makers accountable and ensure that adults genuinely took their views in to account. The inclusion 
of photos, direct quotes and the Youth Advisory Panel's postcards in the final report was also useful in ensuring that children and young people's perspectives were presented in their own words.

However, more could have been done to demonstrate that children and young people's views were presented without filtering from adults. The Expert Panel's final report refers to a process of "synthesising" the interview outcomes (Expert Panel, 2015b, p. 254), but does not describe exactly what that process involved. Additionally, the report does not state how the outcomes from the workshops were used. Children and young people's opinions may well have been taken in to account, but their meaningful participation required a high degree of transparency from adults. The report does not make it clear whether this happened as thoroughly as it should have.

\section{Assumed representation and selection bias}

There was an attempt to have a broad demographic spread across the interviews, workshops and Youth Advisory Panel process. Generally, this was done well, but there were some areas that could have been improved. For example, the Youth Advisory Panel was mainly comprised of older young people, in part due to the pressures of reporting directly to the Minister of Social Development (A. Buchanan, personal communication, May 20, 2016). This meant that younger children were not involved, which may have skewed the outcomes of that process. However, this risk of assumed representation was mitigated by the fact that three different participation mechanisms were used. This ensured a broader range of children and young people's voices were heard.

Selection bias was also an issue. The lack of an established process for selecting children and young people to participate meant that most of those who were involved were already known to Child, Youth and Family or the Office of the Children's Commissioner through previous participation processes. As the Expert Panel's recommendations are implemented it will be important to ensure that a wider range of children and young people's voices are listened to, not just those that have already been heard.

\section{Ensuring that children are able to participate on their own terms}

One of the overarching barriers to meaningful children's participation is that participation often occurs in adult spaces and timeframes (Tisdall, 2015b). This was a challenge for the Expert Panel which had a very tight deadline given the scope of the review. The photography component of the one-on-one interviews addressed this to some extent by allowing the interviewees to contribute their own perspectives. The broad scope of the workshops mitigated against this as well. However, aside from that, children and young people's participation in the review occurred mostly within adult spaces and timeframes. This is one area of the Expert Panel's work that could have been improved.

\section{The value of skilled facilitators}

The presence of skilled, independent adults who could facilitate children and young people's participation was perhaps the greatest strength of the Expert Panel's engagement processes. A human-centred design agency facilitated the interviews, a youth development NGO facilitated the workshops and a representative from the Office of the Children's Commissioner facilitated the Youth Advisory Panel. This ensured that the children and young people involved received the independent support they needed to have their voices heard. Awhina Buchanan's work with the Youth Advisory Panel warrants particular mention. Expert Panel member Duncan Dunlop cited her role in facilitating and supporting the Youth Advisory Panel as the primary factor behind the Youth Advisory Panel's success (personal communication, June 3, 2016). 
The specialist skills that the independent facilitators brought to the process ensured that children and young people were able to make significant contributions to the Expert Panel's work. They achieved this despite the tight timeframes involved and the demands that were sometimes placed on them. The prominence of children and young people's voices in the Expert Panel's final report is testament to their work.

\section{Embedding children and young people's voices in policy and service design}

The release of the Expert Panel's final report signals the beginning of a major overhaul of Aotearoa New Zealand's care and protection system, with detailed design and implementation scheduled to continue over the next four years. The Minister of Social Development has already signalled an intention to include children and young people in this process (Tolley, 2016). This provides a unique opportunity to further involve children and young people in system reform.

It is crucial that the next phase of the review learns from the Expert Panel's work with children and young people: learning from what was done well and what could have been improved. Adults must view children and young people as social actors with unique perspectives to contribute, while also recognising their vulnerability. Decision-makers must take steps to ensure that children and young people's voices are not filtered, and that children and young people who contribute their views are given the opportunity to find out how those views influenced decisions. A broad range of children and young people's voices should be incorporated, with systems in place to ensure that all children and young people are able to participate, not just those who are already known to decision-makers. Children and young people should be able to contribute on their own terms. Most of all, independent facilitators should be available to provide children and young people with the support they may need to have their voices heard.

Some of these considerations could be achieved relatively quickly, such as increasing the transparency of engagement processes by ensuring that the children and young people are told how their opinions influenced decisions. Others will take longer to achieve, such as shifting the dominant sociocultural image of children and young people. Key to realising these changes will be building the systems, processes and culture required to make children and young people's participation meaningful. Each of these things is equally important if we are to build the participation ecosystem described in the literature.

The reason why this matters was summed up by Duncan Dunlop, writing the week after the release of the Expert Panel's report. Dunlop wrote:

The route to this change isn't a poster campaign or a glossy leaflet designed by a marketing firm. The route to change is care experienced people themselves. It will be their testimonies that demonstrate how citizens and communities either discriminated against them or improved their lives by making them feel like they belong. They will motivate people to act. Care experienced people's resonating ability to speak the truth, however hard it is to hear, will be central in keeping this process on course. (Dunlop, 2016, para. 9)

Aotearoa New Zealand now has a unique opportunity to effect this change by building a platform for children and young people to have their voices heard. The release of the Expert Panel's report is a chance to ensure that children and young people's participation in decision-making becomes embedded as a right, not just an added extra. It is imperative that this opportunity is used wisely. 


\section{References}

Ashton, S. (2014). The rights of children and young people in state care. Educational Philosophy and Theory, 46(9), 1082-1088.

Atwool, N. (2006). Participation in decision-making: The experience of New Zealand children in care. Child Care in Practice, 12(3), 259-267.

Bessell, S. (2011). Participation in decision-making in outof-home care in Australia: What do young people say? Children and Youth Services Review, 33, 496-501.

Broad, H. (2013). Review of Child, Youth and Family complaints system. Wellington, NZ: Ministry of Social Development.

Cashmore, J. (2002). Promoting the participation of children and young people in care. Child Abuse and Neglect, 26, 837-847.

Cater, A., \& Overlien, C. (2014). Children exposed to domestic violence: A discussion about research ethics and researchers' responsibilities. Nordic Social Work Research, 4(1), 67-79.

Child, Youth and Family. (2016). The Family Group Conference - Te Toka Tumoana. Retrieved from http://www.practicecentre.cyf.govt.nz/policy/workingwith-maori/resources/the-family-group-conference-tetoka-tumoana.html

Cossar, J., Brandon, M., \& Jordan, J. (2014). "You've got to trust her and she's got to trust you": Children's views on participating in the child protection system. Child \& Family Social Work, 21(1)103-112.

Crowley, A. (2015). Is anyone listening? The impact of children's participation on public policy. International Journal of Children's Rights, 23, 602-621.

Dunlop, D. (2016, April 12). The current reality does not need to be tomorrow's. Retrieved from https://www. whocaresscotland.org/who-we-are/blog/our-chief-executiveasks-what-big-changes-in-new-zealand-mean-for-scotland

Expert Panel. (2015a). Modernising Child, Youth and Family interim report. Wellington, NZ: Author.

Expert Panel. (2015b). Expert Panel final report: Investing in New Zealand's children and their families. Wellington, NZ: Author.

Gray, A. (2002). Increasing the participation of children, young people and young adults in decision making. Wellington, NZ: Ministry of Social Development.

Hart, R. (1992). Children's participation: From tokenism to citizenship. Florence, Italy: UNICEF.

Horwath, J., Kalyva, E., \& Spyru, S. (2012). "I want my experiences to make a difference": Promoting participation in policy-making and service development by young people who have experienced violence. Children and Youth Services Review, 34, 155-162.

James, A. (2004). Understanding childhood from an interdisciplinary perspective: Problems and potentials. In P. B. Pufall \& R. P. Unsworth (Eds.), Rethinking childhood (pp. 25-37). New Brunswick, NJ: Rutgers University Press.

James, A. (2007). Giving voice to children's voices: Practices and problems, pitfalls and potentials. American Anthropologist, 109(2), 261-272.

Lansdown, G. (2010). The realisation of children's participation rights. In B. Percy-Smith \& N. Thomas
(Eds.), A handbook of children and young people's participation: Perspectives from theory and practice (pp. 11-23). London, UK: Routledge.

Le Va. (2016). Pasifika youth participation guide. Retrieved from http://www.leva.co.nz/library/leva/pasifika-youthparticipation-guide

Malone, K., \& Hartung, C. (2010). Challenges of participatory practice with children. In N. Thomas \& B. Percy-Smith (Eds.), A handbook of children and young people's participation: Perspectives from theory and practice (pp. 24-38). London, UK: Routledge.

Marchant, R., \& Kirby, P. (2004). The participation of young children: Communication, consultation and involvement. In B. Neale (Ed.), Young children's citizenship: Ideas into practice (pp. 92-163). York, UK: Joseph Rowntree Foundation.

Mason, J., \& Hood, S. (2011). Exploring issues of children as actors in social research. Children and Youth Services Review, 33, 490-495.

Ministry of Social Development. (2012). The white paper for vulnerable children. Wellington, NZ: Author.

Ministry of Social Development. (2015, April). Terms of reference for the Modernising Child, Youth and Family Expert Panel. Wellington, NZ: Author.

Office of the Chief Social Worker. (2014). Qualitative review of social worker caseload, workload, caseload and workload management. Wellington, NZ: Author.

Percy-Smith, B. (2010). Councils, consultations and community: Rethinking the spaces for children and young people's participation. Children's Geographies, 8(2), 107-122.

Powell, M. A., \& Smith, A. B. (2009). Children's participation rights in research. Childhood, 16(1), 124-142.

Shier, H. (2001). Pathways to participation: Openings, opportunities and obligations. Children \& Society, 18, 107-117.

Shier, H. (2010). Children as public actors: Navigating the tensions. Children \& Society, 24, 24-37.

Sinclair, R. (2004). Participation in practice: Making it meaningful, effective and sustainable. Children and Society, 18, 106-118.

Smith, A. B. (2002). Interpreting and supporting participation rights: Contributions from sociocultural theory. The International Journal of Children's Rights, 10, 73-88.

Smith, M. (2011). Report to the Minister of Social Development and Employment following an Inquiry in to the serious abuse of a nine year old girl and other matters relating to the welfare, safety and protection of children in New Zealand. Wellington, NZ: Ministry of Social Development.

Suaalii, T., \& Mavoa, H. (2001). Who says yes? Collective and individual framing of Pacific children's consent to, and participation in, research in New Zealand. Childrenz Issues, 5(1), 39-42.

The Werry Centre. (2009). Not just another participation model ... guidelines for enabling effective youth consumer participation in $C A M H$ and $A O D$ services in New Zealand. Auckland, NZ: The Werry Centre for Child and Adolescent Mental Health Workforce Development.

Thomas, N., \& Percy-Smith, B. (2012). "It's about changing services and building relationships": Evaluating the development of Children in Care Councils. Child and Family Social Work, 17, 487-496. 


\section{ORIGINAL ARTICLE}

\section{THEORETICAL RESEARCH}

Tisdall, E. K. (2015a). Children and young people's participation. In W. Vandenhole, E. Desmet, D. Reynaert, \& S. Lembrechts (Eds.), Routledge international handbook of children's rights studies (pp. 185-200). London, UK: Routledge.

Tisdall, E. K. (2015b). Addressing the challenges of children and young people's participation: Considering time and space. In T. Gal \& B. F. Duramy (Eds.), International perspectives and empirical findings on child participation (pp. 381-404). Oxford, UK: Oxford University Press.

Tisdall, E. K., \& Davis, J. (2004). Making a difference? Bringing children's and young people's views into policymaking. Children \& Society, 18, 131-142.

Tolley, A. (2016, April 7). The future of child protection and care. Retrieved from https://www.beehive.govt.nz/ speech/future-child-protection-and-care

Treseder, P. (1997). Empowering children and young people training manual: Promoting involvement in decision making. London, UK: Save the Children, UK.

Vaioleti, T. M. (2006). Talanoa research methodology: A developing position on Pacific research. Waikato Journal Education, 12, 21-34.

van Bijleveld, G. G., Dedding, C. W., \& Bunders-Aelen, J. F. (2015). Chidlren's and young people's participation within child welfare and child protection services: A state-of-the-art review. Child \& Family Social Work, $20,129-138$

Vis, S. A., \& Thomas, N. (2009). Beyond talking: Children's participation in Norwegian care and protection cases. European Journal of Social Work, 12(2), 155-168. 